\title{
PERFORMANCE OF THE FIRST REFURBISHED CEBAF CRYOMODULE*
}

\author{
M. Drury, E. F. Daly, G. K. Davis, J. Fischer, C. Grenoble, W. Hicks, J. Hogan, L. King, R. Nichols, \\ T. Plawski, J. Preble, T. Rothgeb, H. Wang \\ Jefferson Lab, 12000 Jefferson Ave, Newport News, VA.
}

\begin{abstract}
The Thomas Jefferson National Accelerator Facility has begun a cryomodule refurbishment project. The goal of this project is robust $6 \mathrm{GeV}, 5$ pass operation of the Continuous Electron Beam Accelerator Facility (CEBAF). The scope of the project includes removing, refurbishing and replacing 10 CEBAF cryomodules at a rate of three per year. Refurbishment includes reprocessing of SRF cavities to eliminate field emission and increase the nominal gradient from the original $5 \mathrm{MV} / \mathrm{m}$ to 12.5 $\mathrm{MV} / \mathrm{m}$. New "dogleg" couplers between the cavity and helium vessel flanges will intercept secondary electrons that produce arcing on the $2 \mathrm{~K}$ ceramic window in the Fundamental Power Coupler (FPC). Modification of the Qext of the FPC will allow higher gradient operations. Other changes include new ceramic RF windows for the air to vacuum interface of the FPC and improvements to the mechanical tuners. Any damaged or worn components will be replaced as well. Currently, the first of the refurbished cryomodules has been installed and tested both in the Cryomodule Test Facility and in place in the North Linac of CEBAF. This paper will summarize the results of these tests.
\end{abstract}

\section{INTRODUCTION}

The first of the refurbished CEBAF cryomodules was completed and installed in the Cryomodule Test Facility (CMTF) in Oct. 2006 for Acceptance testing. After completion of Acceptance testing in November 2006 the cryomodule was prepared for installation in the North Linac of CEBAF. The cryomodule, C50-01, was installed in January 2007 and Commissioned February-April, 2007. Prior to being refurbished, this cryomodule had been in service in the accelerator tunnel since 1992.

During the refurbishment process, the cryomodule was disassembled and the cavities removed and reprocessed to eliminate field emission and increase the nominal gradient from the original $5 \mathrm{MV} / \mathrm{m}$ to $12.5 \mathrm{MV} / \mathrm{m}$ on average. "Dogleg" couplers were installed between the cavity and helium vessel flanges to intercept the secondary electrons that produce arcing on the cold ceramic window of the FPC (see Figure 1). Improved warm ceramic windows were added as well. Improvements were made to the mechanical tuners and any worn or damaged components were replaced.

* This manuscript has been authored by Jefferson Science Associates, LLC under U.S. DOE Contract No. DE-AC05-06OR23177. T he U.S. Government retains a non-exclusive, paid-up, irrevocable, worldwide license to publish or reproduce this manuscript for U.S. Government purposes.
Table 1 lists the tests conducted during Acceptance testing and during Commissioning. This paper will compare the measurements of cavity performance that have been made since the completion of refurbishment with those made during the original commissioning in 1992 and the operational history so far.

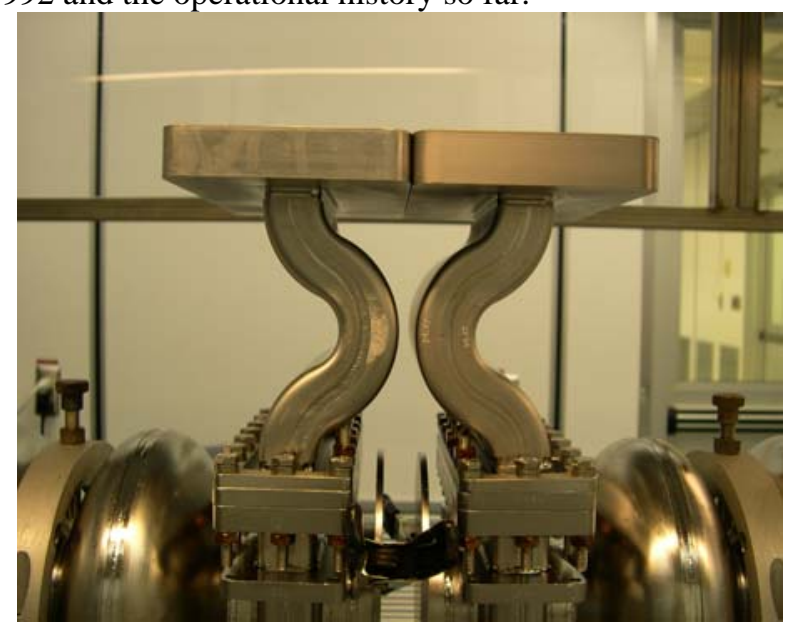

Figure 1: Dogleg couplers

Table 1: Cavity tests

\begin{tabular}{|l|r|r|}
\hline Test & Acceptance & Commissioning \\
\hline $\begin{array}{l}\text { Frequency } \\
\text { Measurements }\end{array}$ & $\begin{array}{r}\text { Warm and } \\
\text { Cold }\end{array}$ & Cold \\
\hline $\begin{array}{l}\text { Tuner Range, } \\
\text { Hysteresis and } \\
\text { Resolution }\end{array}$ & $\mathrm{X}$ & Range Only \\
\hline $\begin{array}{l}\text { Max Gradient } \\
\text { Determination (Emax) } \\
\text { and Extended Run } \\
\text { (Emaxop) }\end{array}$ & $\mathrm{X}$ & $\mathrm{X}$ \\
\hline Field Emission and $\mathrm{Q}_{0}$ & $\mathrm{X}$ & \\
\hline $\begin{array}{l}\text { Qext's FPC and field } \\
\text { probe }\end{array}$ & $\mathrm{X}$ & $\mathrm{X}$ \\
\hline $\begin{array}{l}\text { Lorentz Force Pulse } \\
\text { Response }\end{array}$ & $\mathrm{X}$ & \\
\hline Microphonics & $\mathrm{X}$ & \\
\hline
\end{tabular}




\section{TEST RESULTS}

\section{$Q_{\text {ext }} F P C$ Measurements}

High power tests were performed using the combined output of two $5 \mathrm{~kW}, 1497 \mathrm{MHz}$ klystrons. A VCO/PLL locked to the cavity frequency drives this RF source. The system can deliver either pulsed or CW RF over a large range of pulse rates and duty cycles.

Cavity performance measurements such as Emax determination and $\mathrm{Q}_{0}$ vs. E are conducted using CW RF. Pulsed RF is useful for processing waveguide or beamline vacuums and for measurements of the $\mathrm{Q}_{\mathrm{ext}}$ of the cavity's FPC ( $\left.\mathrm{Q}_{\text {ext }} \mathrm{FPC}\right)$.

$\mathrm{Q}_{\text {ext }} \mathrm{FPC}$ is calculated by pulsing the RF into the cavity and measuring the decay time of the power emitted from the cavity while the RF is turned off.

The design target for $\mathrm{Q}_{\mathrm{ext}} \mathrm{FPC}$ for the reworked cryomodules is $8 \times 10^{6} \pm 20 \%$. The original specification was $6.6 \times 10^{6} \pm 20 \%$. Table 2 shows the measurement results. The measurements made during Acceptance Testing showed that the $\mathrm{Q}_{\mathrm{ext}} \mathrm{FPC}$ tuning was within a factor of two of the target value. After the cryomodule was installed in the tunnel, waveguide stub tuners were used to correct the FPC coupling. The corrected $\mathrm{Q}_{\text {ext }}$ 's are shown in the Commissioning column of Table 2.

Table 2: QextFPC

\begin{tabular}{|c|r|c|}
\hline Cavity & Acceptance & Commissioning \\
\hline 1 & $3.4 \mathrm{E}+06$ & $8.1 \mathrm{E}+06$ \\
\hline 2 & $2.0 \mathrm{E}+06$ & $7.5 \mathrm{E}+06$ \\
\hline 3 & $2.8 \mathrm{E}+06$ & $8.8 \mathrm{E}+06$ \\
\hline 4 & $4.2 \mathrm{E}+06$ & $8.0 \mathrm{E}+06$ \\
\hline 5 & $3.0 \mathrm{E}+06$ & $8.1 \mathrm{E}+06$ \\
\hline 6 & $2.8 \mathrm{E}+06$ & $7.8 \mathrm{E}+06$ \\
\hline 7 & $3.6 \mathrm{E}+07$ & $3.7 \mathrm{E}+07$ \\
\hline 8 & $1.5 \mathrm{E}+07$ & $6.4 \mathrm{E}+06$ \\
\hline
\end{tabular}

\section{Maximum Gradient}

Once the $Q_{\text {ext }}$ 's have been measured and gradients can be calculated, the next step is to determine the maximum gradient for a given cavity. The maximum gradient, Emax, is defined here as the highest gradient attainable before some condition causes the machine protection interlocks to turn off the RF power. These limiting conditions include cavity quenches, degraded waveguide or beamline vacuum, heating associated with the ceramic windows or arcing in the waveguide vacuum space. The RF power delivered to a cavity is slowly increased while looking for limiting conditions. Part of the process of determining Emax involved using the RF to clean up the waveguide vacuum space for each cavity.

Once Emax is determined, a stable maximum gradient has to be determined. That is defined here as the highest gradient that may be maintained in a cavity for at least one hour. This is the maximum operating gradient or Emaxop. Figure 2 illustrates the effect that refurbishment has on the maximum operating gradient. The nominal target gradient for the reworked cryomodules is 12.5 $\mathrm{MV} / \mathrm{m}$ and is represented by the red horizontal line.

Table 3 contains information on limiting factors. Some of the limits that were imposed during the original installation in 1992 are no longer applied. These conditions include radiation from field emission in excess of $1 \mathrm{R} / \mathrm{hr}$ and a dynamic heat load due to field emission greater than $1 \mathrm{~W}$. These early constraints were effectively replaced by the phenomenon of periodic window arcing. This is the phenomenon that the dogleg coupler is designed to prevent. None of the cavities in the reworked cryomodule have experienced this problem, so far.

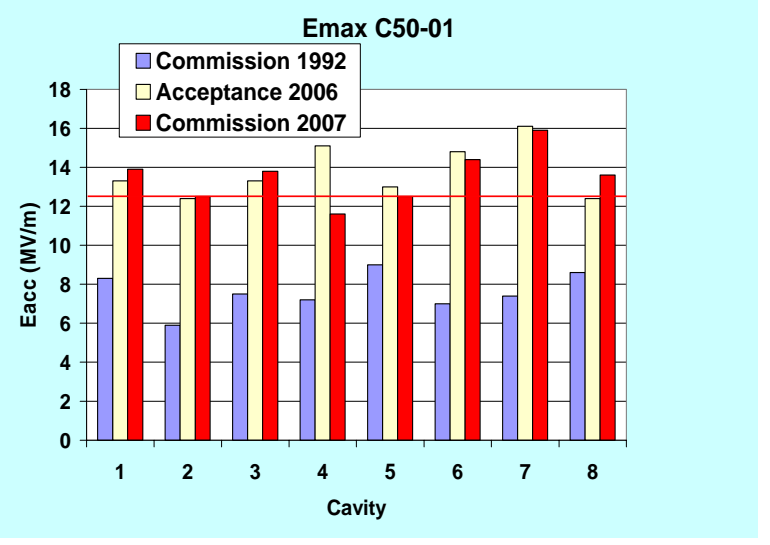

Figure 2: Maximum Gradients

\section{Field Emission}

Another measure of cavity performance is the amount of field emitted radiation produced at a given gradient. A series of Geiger-Mueller tubes were placed around the cryomodule during high power testing. During acceptance testing, only three cavities generated radiation. No radiation was detected from any cavities during commissioning. Table 4 summarizes the results. During the 1992 commissioning, field emission was detected in five cavities with onsets as low as $3 \mathrm{MV} / \mathrm{m}$ and radiation levels as high as $1 \mathrm{R} / \mathrm{hr}$.

Table 3: Gradient Limits

\begin{tabular}{|l|l|l|l|}
\hline Cavity & $\begin{array}{l}\text { Commission } \\
\text { 1992 }\end{array}$ & $\begin{array}{l}\text { Acceptance } \\
\text { 2006 }\end{array}$ & $\begin{array}{l}\text { Commission } \\
\mathbf{2 0 0 7}\end{array}$ \\
\hline 1 & Quench & $\begin{array}{l}\text { FPC Flange } \\
\text { Temp }>100 \text { C }\end{array}$ & Quench \\
\hline 2 & $\begin{array}{l}\text { Reflected } \\
\text { Power Trip }\end{array}$ & Quench & Quench \\
\hline 3 & Quench & Quench & $\begin{array}{l}\text { Waveguide } \\
\text { Vacuum }\end{array}$ \\
\hline 4 & $\begin{array}{l}\text { Waveguide } \\
\text { Arcs }\end{array}$ & $\begin{array}{l}\text { Waveguide } \\
\text { Vacuum }\end{array}$ & Quench \\
\hline 5 & $\begin{array}{l}1 \text { R/hr Field } \\
\text { Emission }\end{array}$ & $\begin{array}{l}\text { Klystron } \\
\text { Power Limit }\end{array}$ & $\begin{array}{l}\text { Warm } \\
\text { Window } \\
\text { Temp }\end{array}$ \\
\hline 6 & $\begin{array}{l}\text { Beamline } \\
\text { vacuum }\end{array}$ & $\begin{array}{l}\text { Waveguide } \\
\text { Vacuum }\end{array}$ & $\begin{array}{l}\text { Waveguide } \\
\text { Vacuum }\end{array}$ \\
\hline 7 & Quench & Quench & Quench \\
\hline 8 & Quench & Quench & Quench \\
\hline
\end{tabular}


Table 4 Field Emission

\begin{tabular}{|c|c|c|}
\hline Cavity & $\begin{array}{c}\text { Field Emission } \\
\text { Onset (MV/m) }\end{array}$ & $\begin{array}{c}\text { Maximum } \\
\text { Radiation Level } \\
\text { (mR/hr) }\end{array}$ \\
\hline 5 & 9.4 & 125 \\
\hline 7 & 9.1 & 350 \\
\hline 8 & 8.6 & 130 \\
\hline
\end{tabular}

\section{$Q_{0}$ Measurements}

The final measure of cavity performance considered here is $\mathrm{Q}_{0}$ or unloaded $\mathrm{Q}$. A calorimetric method is used to measure $\mathrm{Q}_{0}$. Measuring changes in the rate of rise of helium pressure in a cryogenically isolated cryomodule allows us to calculate $\mathrm{Q}_{0}$ and the RF heat load at a given accelerating gradient. The target for $\mathrm{Q}_{0}$ in a reworked cryomodule is $6.8 \times 10^{9}$ at $12.5 \mathrm{MV} / \mathrm{m}$ and at $2.1 \mathrm{~K}$. Figure 3 shows the results for this measurement during the Commissioning test. The results are similar to those measured during Acceptance testing. It should be noted that none of the cavities were able to reach the target specification. On average, these measurements are about a factor of 2 lower than measurements made on the cavities in the Vertical Test Area prior to assembly into the cryomodule.

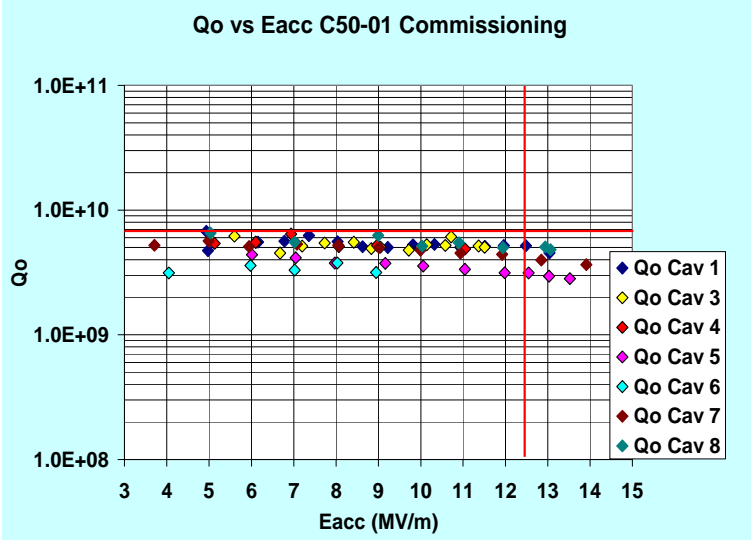

Figure 3: $Q_{0}$ vs. Eacc in 2007

Figure 4 shows the results for this cryomodule when it was first tested in 1992

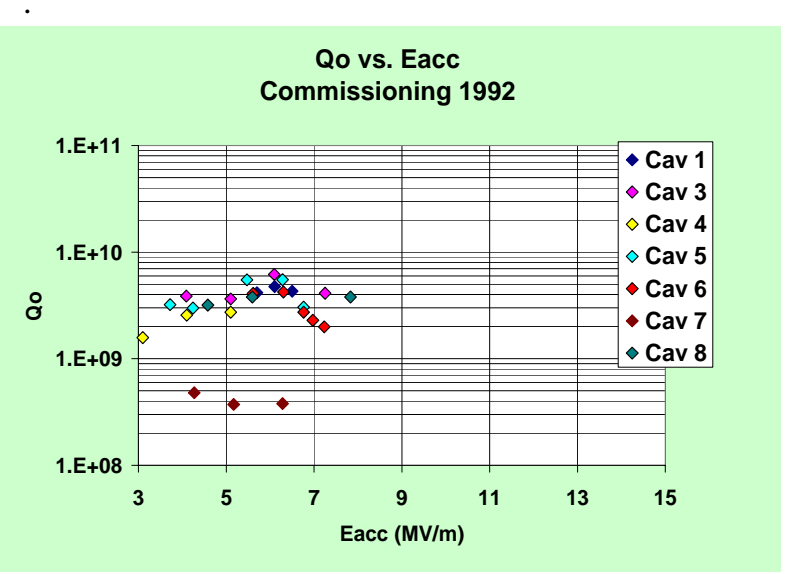

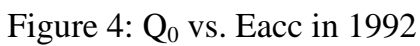

\section{Current Status}

The cryomodule, C50-01 is currently in operation in the CEBAF accelerator and has been since May 2007. Currently, one cavity, Cavity 4 is turned off due to a problem with a warm window temperature monitor. The other seven cavities are delivering a total energy gain of $39.2 \mathrm{MeV}$. If all eight cavities were working, the cryomodule could deliver $44.8 \mathrm{MeV}$. It is expected that more experience with this cryomodule will allow operation at $49 \mathrm{MeV}$, close to the $50 \mathrm{MeV}$ target. Figure 5 compares Emaxop as determined at different times both before and after refurbishment. At the time of its first installation this cryomodule had the potential to deliver 25 $\mathrm{MeV}$. Figure 6 is a graph of the total RF fault count since May 1, 2007.

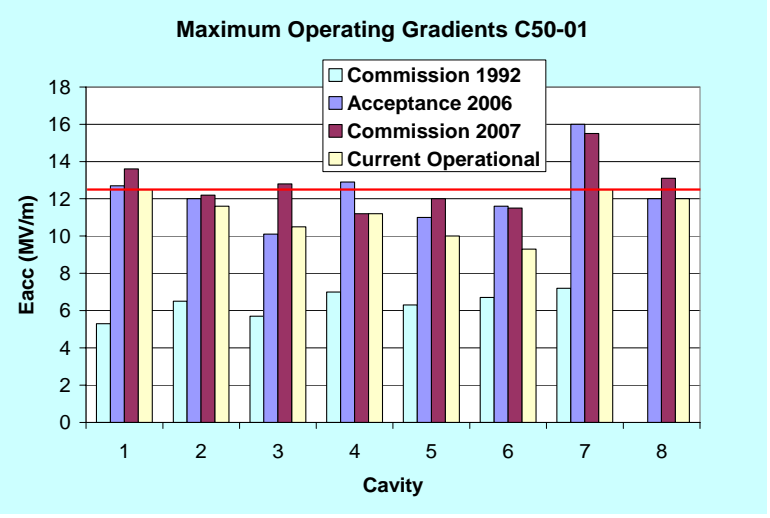

Figure 5: Operating Gradient History

The total fault count is higher than the cryomodule average for this period. Major contributors to this total are waveguide vacuum faults and "turn-on" problems leading to quenches, which should decrease over time.

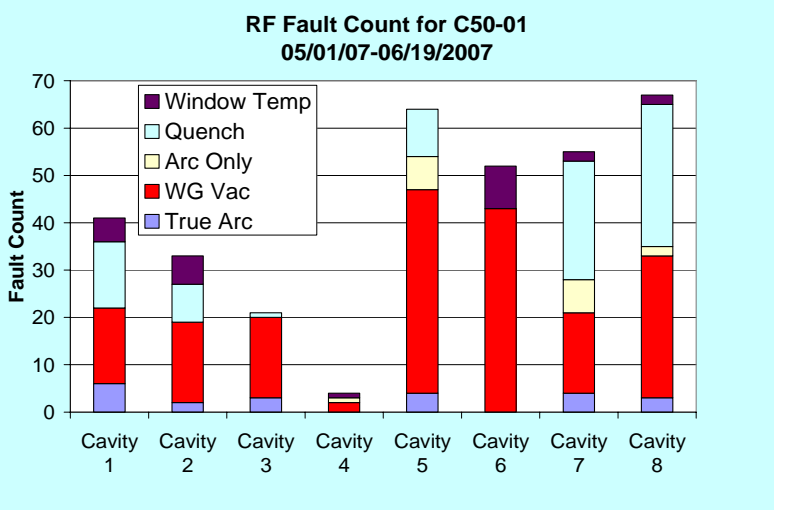

Figure 6: RF Fault Counts for C50-01

\section{CONCLUSION}

This cryomodule is the first of the reworked cryomodules. There is room for improvement in the tuning of the FPC couplings (QextFPC) and the target $\mathrm{Q}_{0}$ for these cavities has not yet been reached. However, the cryomodule is capable of reliably delivering up to 44.8 $\mathrm{MeV}$, which is almost double the energy of the original cryomodule. 